\title{
SZTUKA WIELKOFORMATOWA NA TLE ARCHITEKTURY, ZJAWISKO I JEGO WPŁYW NA PERCEPCJĘ PRZESTRZENI I FORMY ARCHITEKTONICZNEJ
}

DOI: 10.37660/integr.2020.6.2.2

\section{WSTĘP}

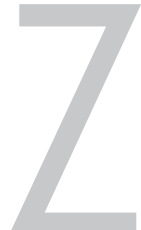

abudowa miejska, jej elewacje i sq̨siadujace z niq przestrzenie publiczne zawsze były interesujacym obszarem dla ekspresji artystycznej. Sztuka była i jest towarzyszem przechodnia w przestrzeni miejskiej i w zależności od swojego wyrazu oraz tematyki przyjmuje rozmaite role i z różna intensywnościa wpływa na przestrzeń architektoniczna'. Zanim zastanowimy się nad misja rozpatrywanych dzieł sztuki, należy określić zakres poszukiwań materiału. Ze względu na powszechność i intensywność zjawiska ${ }^{2}$ można by nie ograniczać obszaru badań w aspekcie geograficznym, ponieważ szłuka występuje wszędzie tam, gdzie żyje człowiek. Jednak z uwagi na wybrany do rozważań problem, jakim jest wpływ sztuki na percepcję przestrzeni i formy architektonicznej, wybrano przykłady z europejskich przestrzeni publicznych, ponieważ percepcja, mimo że jest indywidualna, nie jest wolna od kulturowych wpływów, a te są bardziej zbliżone do siebie w obrębie tego samego kontynentu³. Poruszając się ulicami miast, możemy zauważyć właściwie każda znana formę działalności artystycznej - od malarstwa, poprzez rzeźbę, aż do happeningu, która zawiera się w pojęciu „sztuka ulicy” lub „street art"4. Na potrzeby publikacji autorka skupiła się jedynie na dziełach wizualnych eksponowanych na tle elewacji, ponieważ ich kontakt jest bezpośredni ze struktura architektoniczna ${ }^{5}$. Najbardziej popularne w tej grupie sa murale, graffiti,

dr inż. arch. Małgorzata Kaus, https://orcid.org/0000-0002-6035-835X, Katedra Architektury i Urbanistyki, Wydział Budownictwa, Architektury i Inżynierii Środowiska, Uniwersytet Technologiczno-Przyrodniczy im. Jana i Jędrzeja Śniadeckich w Bydgoszczy, m-kaus@wp.pl

1 Przestrzeń architektoniczna jest to przestrzeń szłuczna ułworzona przez człowieka, kłóra jak stwierdził Christian Norberg-Schulz, składa się z takich elementów, jak miejsce, droga i strefa. [W:] Ch. Norberg-Schulz, 2000. Bycie, przestrzeń i architektura. Wyd. Murator, s. 7-14.

2 Intensywność zjawiska potwierdzaja punkty na mapach z lokalizacja murali powstałych w ramach licznych festiwali odbywających się w Polsce, np.: warszawskiego Street art doping, łódzkiego Urban forms festiwal, poznańskiego Outer spaces, katowickiego Street art festiwal. Tylko $w$ Łodzi jest ponad 70 murali w przestrzeni miasta.

3 Hipoteza Sapira-Whorfa - na proces myślowy ma wpływ język, jakim się posługujemy. [W:] A. Klimczuk, 2013. Hipoteza Sapira-Whorfa-przegląd argumentów zwolenników i przeciwników. Kultura -Społeczeństwo - Edukacja, 1 (3), s. 165-181, Adam Mickiewicz University Press, Poznań.

${ }^{4}$ Za: W. Moch, Sztuka ulicy obejmuje wszystkie działania artystyczne w przestrzeni ulicy, street art. Ma bardziej wyszukaną formę, technikę, ale zawiera się w pojęciu sztuk ulicy, jednak właściwe wydaje się być stosowanie pojęć wymiennie z uwagi na różne stosowane definicje; [W:] W. Moch, 2016. Street art i graffiti. Litery, słowa i obrazy w przestrzeni miasta. Wydawnictwo Uczelniane Wyższej Szkoły Gospodarki \& Włodzimierz Moch, Bydgoszcz, s. 19.

5 Za: Buczyńska-Garewicz, powołujac się na Heideggera, odróżnia przestrzeń mierzalna od przestrzeni przeżywania; [W:] H. Buczyńska-Garewicz, 2006. Miejsca, strony, okolice. Przy- 
malarstwo i nieco mniej płaskorzeźba i fotografia. Podział między tymi grupami jest dość niejednoznaczny i nie zawsze te same uwarunkowania wpływaja na zakwalifikowanie dzieła do danej grupy. Na przykład zgodnie z teoria McLuhana ${ }^{6}$ kluczowym aspektem w rozważaniach na temat twórczości artystycznej jest medium i to ono określa dzieło, natomiast A. Niżyńska w swojej książce pt: „Street art jako alternatywna forma debaty publicznej w przestrzeni miejskie"7 używa idei i celu artysty jako czynnika definiujacego dzieło. Dlatego zaznaczam, że z uwagi na podjęty temat klasyfikacja dzieła nie jest prioryłetem ani tematem badań. Ważne jest natomiast, jak dzieło umieszczone na tle architektury zmienia jej odbiór i to jest kluczowe zagadnienie w dalszych rozważaniach. Jednak w tytule użyło pojęcia sztuka wielkoformatowa i tu z uwagi na specyfikę łła, jakim jest struktura architektoniczna miejskiej przestrzeni publicznej, przyjęto założenie, że dzieło nie powinno być odbierane bez łła, na którym występuje, stąd nie tylko jego wymiary określaja, czy jest postrzegane jako wielkoformatowe. Wyjaśnieniem przyjętej zasady moga być dzieła Banksy'ego, kłóre wykorzystuja walory zastanej struktury architektonicznej. Na przykład mural, który pojawił się z okazji dnia Świętego Walentego ${ }^{8}$ na szczytowej ścianie jednego z budynków w mieście Bristol i przedstawia chłopca strzelającego kwiatami z procy, mimo że formalnie nie zajmuje całej elewacji, odbierany jest w pełnym jej obszarze, ponieważ składa się z dwóch połączonych ze soba tematycznie elementów i przestrzeni pomiędzy nimi. Fakł umieszczenia działa sztuki na formie, która została wybrana przez artystę, a nie powstała z założeniem, że będzie narzędziem ekspozycji artystycznej, uznano w tym opracowaniu za powód odbioru obu tych składników jako całości wizualnej.

\section{ROLA SZTUKI W PRZESTRZENI PUBLICZNEJ}

Historyczne przykłady występowania wielkoformatowych artystycznych przedsięwzięć, takich jak na przykład murale w Belfaście W Irlandii (rys. 1)9 czy meksykańskie murale Diego Rivery ${ }^{10}$ oraz aktualne prace takie, jak mural poświęcony Korze autorstwa Bruno Althamera ${ }^{11}$ czy ostatnio wykonany w Gdańsku projekł w hołdzie dla pracowników służby zdrowia (rys. 2), a także popularne stwierdzenia na temat działań artystycznych w przestrzeni publicznej pozwalaja myśleć o szczególnej roli dzieł sztuki w agitacji politycznej, aspekcie historycznym, społecznym, kulturowym i edukacyjnym.

Taką rolę dostrzegają w ekspozycji sztuki w przestrzeni miast ich włodarze. Jednak część artystów zwraca uwagę na brak wolności, kluczowego aspektu sztuki.

czynek do fenomenologii przestrzeni. Wyd. Universitas, Kraków, s. 69, 52.

6 Za McLuhan, stwierdzenie "the medium is the message" dotyczyło postrzegania środka komunikacji jako komunikatu; M. McLuhan, Now The Medium Is The Massage. New York Times (dostęp: 04.09.2018).

7 A. Niżyńska, 2011 . Street art jako alternatywna forma debaty publicznej w przestrzeni miejskie. Wyd. Trio, Warszawa.

8 https://www.banksy.co.uk/out.asp (dostęp: 29.06.2020).

9 Tematem dzieł był konflikt w Irlandii Północnej między katolikami nacjonalistami a protestanckimi unionistami; R. Kerr, 2014. The Belfast Mural Guide, Wyd. MSF Press.

10 Diego Rivery - twórca meksykańskich murali, malarz, grafik, architekt, działacz polityczny ruchu komunistycznego, mąż Fridy Kahlo.

11 Mural poświęcony Korze oparty na idei zmienności, wykonany na tle ściany, skomponowany wraz ze zmieniajacym się wraz z porami roku drzewem, autor: Bruno Althamera, Nowy Świat Warszawa 18/20, 2019. 
Większość aktualnie widocznych w miastach murali powstaje pod czyjąś kuratela i porusza tematy społecznie akceptowalne lub oparte na utartych schematach ideowych, bez dodatkowej informacji pogłębiającej przedstawiony temat, stąd wątpliwości co do kształtowania wartości, jakie sa komunikowane odbiorcy i roli sztuki w przestrzeni publicznej. Zagadnienia te zostały szerzej opracowane w badaniach pt. „Mury. Diagnoza dynamiki środowiska twórców malarstwa monumentalnego"12. Artyści, ulegajac wpływom, wpadaja w pułapkę komercji, czasami nacisków zewnętrznych, sami ograniczaja swoja wolność twórcza i sprowadzają rolę sztuki w przestrzeni publicznek jedynie do estetyzacji miasta. Komercyjny charakter pracy, a właściwie ograniczenia tematyczne, czasowe, przestrzenne powoduja, że część artystów rezygnuje z ekspozycji w przestrzeni publicznej lub realizuje się $w$ działaniach nielegalnych i z uwagi na krótki czas realizacji wybiera graffiti jako formę przekazu artystycznego. Sztuce przypisuje się wiele właściwości, kłóre maja wpływać na zmianę miejskich obszarów. Czasami jest przedstawiana w aspekcie rewitalizacji tkanki miejskiej, co kwestionuja artyści i godza się jedynie ze stwierdzaniem, że ich twórczość to pierwszy impuls do ewentualnych dalszych zmian jakościowych tkanki architektonicznej. Wspomniane powyżej wyniki badań pokazuja, jak postrzegane

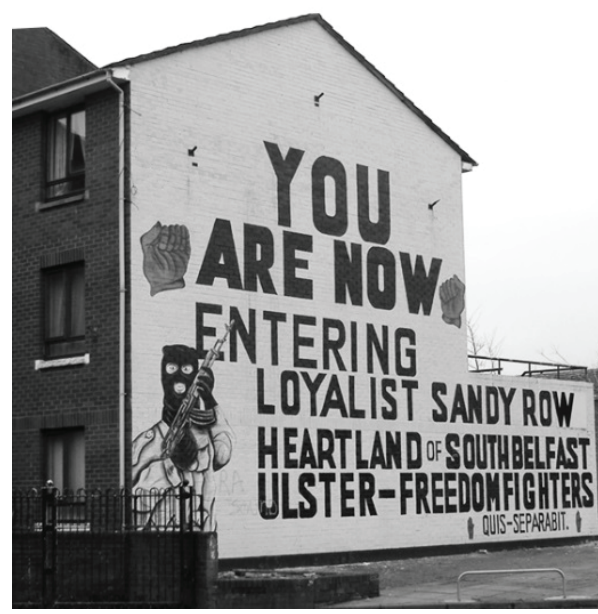

Rys. 1. Murale wyrazem konfliktu w Irlandii Północnej między katolikami nacjonalistami a protestanckimi unionistami, Belfast (fot. autor, 2005)

Fig. 1. Murals express conflict in Northern Ireland between Catholic nationalists and Protestant unionists, Belfast (photo by author, 2005)

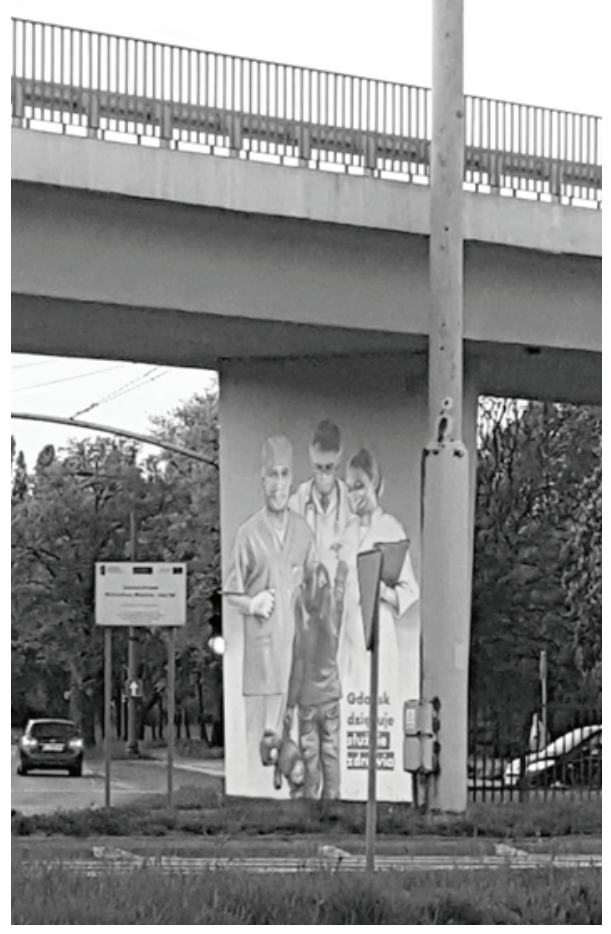

Rys. 2. Hołd dla pracowników służby zdrowia walczacych z pandemia COVID-19, autor: Marek Looney Rybowski, 2020 (fot. autor, 2020)

Fig. 2. Tribute to healthcare workers fighting the COVID-19 pandemic, author: Marek Looney Rybowski, 2020 (photo by author, 2020)

\footnotetext{
12 M. Duchowski, J. Drozda, B. Kopczyński, A. Litorowicz, A. Pietraszko, Z. Rojek, E. Welter, K. Wittels 2017; projekt badawczy „Mury. Diagnoza dynamiki środowiska twórców malarstwa monumentalnego" był realizowany przez Instytut Badań Przestrzeni Publicznej w partnerstwie z Centrum Sztuki Współczesnej , Łaźnia” oraz Muzeum Współczesnym Wrocław.
} 
jest zjawisko dzieła w przestrzeni publicznej przez różne grupy społeczne. Jednak do pełnego obrazu zabrakło mi głosu architektów jako profesjonalistów kształtujących przestrzeń architektoniczna. Mariusz Kaznowski w opracowaniu pt.: „Mur(al) owe podwoje do przeszłości - murale jako nośniki kultury historycznej na przykładzie wybranych prac w południowo-wschodniej Polsce" dostrzega w tej sytuacji szczególna rolę architektury, mówiąc, że „Mur i ściana moga się stawać obszarami podziału i/lub łączenia także we współczesnej szłuce przestrzeni publicznej"13.

\section{WPKYW SZTUKI NA PERCEPCJĘ PRZESTRZENI I FORMY ARCHITEKTONICZNEJ}

Rola architektury w percepcji sztuki, która jest na jej tle eksponowana, jest oczywista, ale dzieło sztuki jako silnie koncentrujący uwagę odbiorcy element w przestrzeni wpływa na percepcję otaczajacej tkanki miejskiej. Na przykładzie kilku przedsięwzięć artystycznych przedstawiono zmianę w odbiorze relacji przestrzennych po wprowadzeniu dzieła wizualnego do danej przestrzeni publicznej. Odbiór sztuki, kłóra powstaje w tym samym czasie, stylu i we współpracy z architektem jest tożsamy z odbiorem architektury, a z upływem lat dzieło staje się jego integralna częścia i postrzegane jest jak harmonijna całość założenia architektonicznego. Jednak współpraca artysty i architekta nie jest częstym zjawiskiem, na ogół sztuka jest elementem dodanym do istniejącej przestrzeni i z założenia postrzegana jest jako element czasowy i ruchomy. Jednak czas ekspozycji, który bywa również okresem żywotności dzieła, to czasami zakres od kilku do kilkunastu lat. Dlatego istnieje możliwość, że przynależność dzieła szłuki do miejsca powoduje, że może ono mieć wpływ na budowanie tożsamości przestrzennej u odbiorców i na stałe wpisać się w postrzeganie danej części miasta. Zgodnie z przyjętym przez Christiana Norberta-Schulza podziałem przestrzeni ${ }^{14}$ dzieło szłuki wpisuje się w przestrzeń percepcyjna z uwagi na swoja zmienność i egocentryzm twórczy oraz fakt bycia zdarzeniem na osi czasu istnienia tkanki architektonicznej. Bardzo ciekawym przykładem, w którym sztuka wkracza w egzystencjonalny wymiar przestrzeni, jest projekt fotograficzny pt: "Quanta strada nei miei sandali”15, eksponowany na ścianach historycznej części miasta Alghero na Sardynii. Projekt jest ważny pod względem społecznym, ponieważ artystka Daniela Zedda odnosi się do tożsamości tego miejsca poprzez nie tylko miejsca ekspozycji, ale przede wszystkim poprzez temat poruszony w fotografiach. Autorka uwieczniła w swoich pracach sylwetki mieszkańców, kłórzy ukończyli sto lat. Pokazała ich codzienne akływności w ważnych przestrzeniach miasta, przez co umożliwiła innym mieszkańcom i turystom pośrednio wgląd w prywatna strefę miasta. To zatarcie granicy pomiędzy tym, co publiczne a tym, co prywatne powoduje, że poprzez sztukę odbiorcy moga poczuć tożsamość miejsca. Dzieło sztuki wpisuje się w teorię potrzeby budowania przestrzeni egzystencjonalnej, jest odpowiedzią na tęsknotę za poczuciem „zamieszkiwania"16, które jest rzadkością w wyludniających się centrach współ-

${ }^{13}$ M. Kaznowski, 2018. Mur(al)owe podwoje do przeszłości - murale jako nośniki kultury historycznej. Zeszyły Naukowe Towarzystwa Doktorantów Uniwersytetu Jagiellońskiego, Nauki Społeczne, Kraków.

${ }^{14}$ Przestrzeń: architektoniczna, percepcyjna, ekspresyjna, egzystencjonalna. [W:] Ch. Norberg-Schulz, 2000. Bycie, przestrzeń i architektura. Wyd. Murator.

15 "Quanta strada nei miei sandali" artystka Daniela Zedda, http://www.danielazedda.it/.

16 wg M. Heideggera „zamieszkiwać” tzn. być, mieszkać w sensie egzystencjonalnym, doświadczać przestrzeni; M. Heidegger, 1974. Budować, mieszkać, myśleć. Teksty: teoria lite- 
czesnych miast. Wybór miejsca ekspozycji zawierał się w wyjściowych założeniach ideowych projektu, ale niestety w detalach rozmieszczenie wydruków fotografii nie wyglada na przemyślane. Pieszy w mieście, pozbawiony „śluzy psychologicznej”"17, nie jest przygotowany na odbiór sztuki, a jego koncentracja nie jest skupiona tylko na prezentowanym dziele. Wymiary prac, a przede wszystkim przypadkowe umocowanie, brak czytelnych reguł kompozycji z innymi elementami elewacji i ołaczających form architektonicznych oraz umiejscowienie dzieła znacznie powyżej poziomu widzenia człowieka utrudniaja percepcję prac. Chaołyczne ich rozmieszczenie nieznacznie wpływa na odbiór formy architektonicznej, ale w większości łłem dla tych prac stały się budynki niebędace kluczowymi pod względem funkcji ani struktury architektonicznej. Wykorzystywanie muzealnych zasad ekspozycji w przestrzeni publicznej działa i jest korzystne dla percepcji dzieł sztuki, ale nie zawsze dla architektury i schematu, według którego zbudowano dana przestrzeń architektoniczna. Zastosowanie przedpola podkreśla rangę widoku, zasada ta działa tak silnie, że na przykład fotografia sylwetki Jana Pawła II, umieszczona na ścianie kamienicy w Alghero (rys. 3), znacznie mniejsza niż łło zwraca uwagę i zmienia siłę odbioru pozostałych obiektów w przestrzeni. Po drugiej stronie uliczki Via Manno, przy jej przedłużeniu, znajduje się gotycka Katedra Niepokalanego Poczęcia Najświętszej Maryi Panny, jednak to zdjęcie przyciaga uwagę przechodnia, a nie Katedra. Ta relacja: małe zdjęcie na tle znacznej ściany działa na zasadzie kontrastu skali i estetyki. Sztuka czasami zakłóca utarty w odbiorze schemat struktury architektonicznej, ale to od trwałości i siły znaczenia tej struktury zależy odbiór dzieła. Jeżeli zachwiana zostanie proporcja dzieła sztuki w stosunku do łła architektonicznego, nie będzie możliwa do odczytu ich relacja estetyczna i przestrzenna.

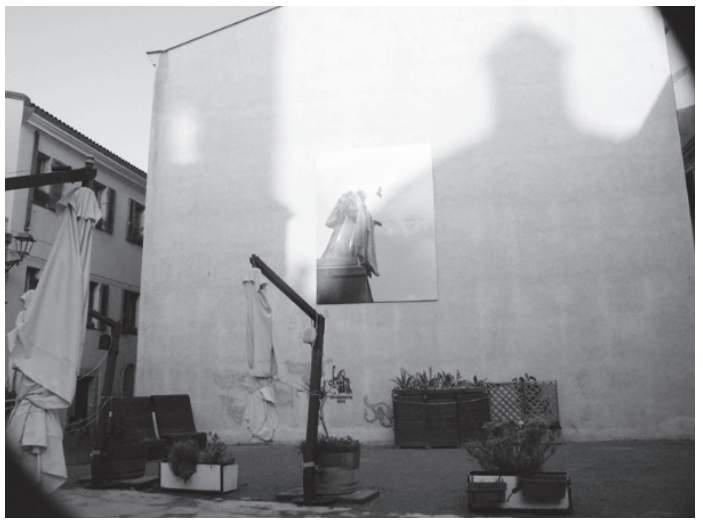

Rys. 3. Fotografia przedstawiajaca sylwetkę papieża Jana Pawła II eksponowana na szczyłowej ścianie w niezabudowanym kwartale przy ulicy Via Manno (fot. autor, 2020)

Fig. 3. A photograph showing the silhovette of Pope John Paul II displayed on the gable wall in an undeveloped quarter on Via Manno (photo by author, 2020)

K. Lynch ${ }^{18}$ zwraca uwagę na zachowanie ciagłości i hierarchii w przestrzeni publicznej. Sztuka nie powinna zmieniać charakteru miasta, którego nadal

ratury, krytyka, interpretacja, $\mathrm{nr}$ 6(18), 137-152.

17 „śluza psychologiczna" przestrzeń izolowana od bodźców zewnętrznych potrzebna do adaptacji psychologicznej, stosowana muzeach przed wejściem do miejsca ekspozycji sztuki; Z. Żygulski, 1981. Przestrzeń muzealna. [W:] Mecenas, kolekcjoner, odbiorca, Materiały Sesji Stowarzyszenia Historyków Sztuki, Katowice, listopad 1981, Warszawa 1984, 243255.

${ }^{18}$ Miasto, regiony, uliczki, zabudowa pośrednia moga się zmieniać, ale kluczowe elementy, takie jak węzły i ważne punkły orientacyjne, kierunki powinny być zachowane. Lynch uważa spójność obrazu przestrzeni miejskiej z tym, co nowe, dodane, związane życiem w mieście jako warunek konieczny do zachowania idei miasta; K. Lynch, 1990. The image of the city. Wyd. Kevin Lynch, The Image of the City M.I.T. Press, Londyn, 109. 


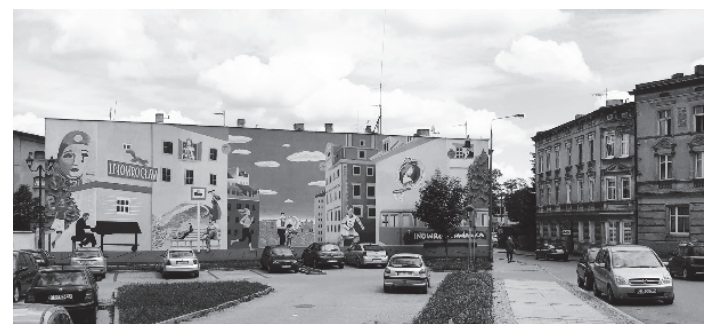

Rys. 4. Mural „Inowrocław w pigułce", autor: Marcin Fołda 2017 (fot. autor, 2020)

Fig. 4. Mural "Inowrocław in a nutshell", author: Marcin Fołda, 2017 (photo by author, 2020)

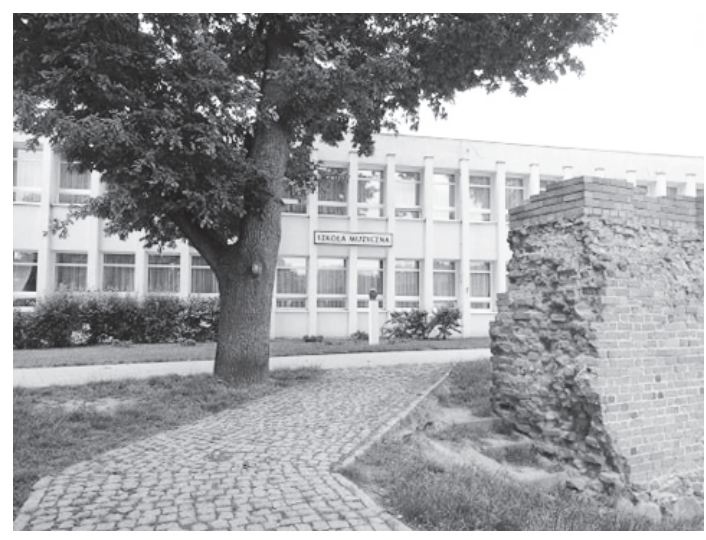

Rys. 5. Tkanka miejska w pobliżu Muralu „Inowrocław w pigułce" - widok na szkołę Muzyczna i fragment murów miejskich (fot. autor, 2020)

Fig. 5. Urban tissue near the "Inowrocław in a nutshell" mural - view of the Music School and a fragment of the city walls (photo by author 2020)

dwigi, prowadzącej od średniowiecznego rynku, dodatkowo leży na trasie pieszej o nazwie „Szlak Jana Kasprowicza”. Po prawej stronie znajduje się neoromański Kościół Świętego Krzyża, po lewej fragment średniowiecznych Murów Miasta i powstawały w latach 80. XX wieku budynek mieszczący w swoim środku bibliotekę miejska, teatr, Inowrocławski Dom Kultury, szkołę muzyczna oraz salę koncertowa. Wszystkie te budynki wraz ze degradowana zabudowa kwartału kamienic tworzyły do tej pory, mimo różnych okresów powstawania, jednolity charakter estetyczny, oparty na naturalnych, szlachetnych materiałach i stonowanych kolorach (rys. 5). Dzieło w mojej opinii zakłóciło ten obraz. Powstało na zniszczonej ścianie i artysta tematycznie nawiązał do wszystkich ważnych atrakcji miasta, stąd entuzjastyczny odbiór mieszkańców, jednak ze szkoda dla łła architekłonicznego. Miejsce to bez wątpienia powinno zostać zastapione kubatura w wymiarze i stylistyce pasujaca

\footnotetext{
19 Praca malarska została wykonana na ścianie kamienicy przy ul. Kilińskiego w Inowrocławiu na powierzchni $250 \mathrm{~m}$ (wymiary $29 \times 8 \mathrm{~m}$ ). Praca różnorodna tematycznie przedstawia wiele aktywności ważnych dla turystyki miasta i wizerunki ważnych obiektów w Inowrocławiu; autor: Marcin Fołda, inwestor: miasto Inowrocławia, 2017.
} 
do wyrazu otoczenia. A charakter miejsca autentyczny, trochę zaniedbany, różnorodny ${ }^{20}$, a jednocześnie spójny, to atut tego miejsca.

Fakt kreacji i odbioru sztuki w kontekście miejsca, mimo że poruszany przy większości projektów przez artystów, kuratorów i odbiorów, bywa niezrozumiały. Dowodem na to jest sposób prezentowania, dokumentowania, powielania prac artystycznych bez pokazania kontekstu. Przykładem takiego działania może być praca „Bubble Slide Girl”21, do której wykonania przyznał się Banksy. Graffiti powstało na ścianie budynku Youth Club w Hackney we wschodniej części Londynu i przestawiało dziewczynkę robiaca bańki mydlane. Artysta wykorzystał istniejąca rurę spustowa i umieścił postać dziewczynki w taki sposób, jakby zjeżdżała po tej rurze. To typowe działanie artysty, ponieważ wszystkie prace Banksy'ego sa osadzone w kontekście przestrzennym. Jednak na stronie artysty praca jest pokazana we fragmencie i nie widać pełnego kontekstu miejsca. Podobnie pokazywana jest większość reprodukcji sprzedawanych jako plakaty czy naklejki. To pokazuje, że nawet artysta, który tworzy w oparciu o konkretna przestrzeń, nie zawsze włącza ja w zakres swojego dzieła ${ }^{22}$. W sytuacji, kiedy sztuka powstaje zgodnie z uwarunkowaniami miejsca, najczęściej jest tak eksponowana, że dopełnia istniejaca kompozycję przestrzenna, nawet gdy jest w kontraście estetycznym. Projekt fotograficzny „Paesani”"23 wykonany w czasie Festiwalu literatury w mieście Gavoi na Sardynii, przez wspomniana wcześniej w tym opracowaniu Danielę Zeddę, jest przykładem sztuki w kontekście przestrzeni architekłonicznej. Artystka uwieczniła wizerunki uczestników wydarzenia w pozycjach i miejscach codziennego życia mieszkańców. Ich wycięte sylwety opierały się o drzwi, wychylały się z okien, zostały wpasowane z zabudowę miasta, które stało się nie tyle łłem, co scenografia dla tego projektu. Sztuka może odczytać tożsamość miejsca, a nawet jeżeli jest site-specific ${ }^{24}$, czyli „specyficzne dla miejsca, w którym się pojawiły", może ja dopełniać. Artyści podkreślaja jednak trudność odczytu tożsamości w sposób właściwy, nie oparty na powielanych schematach. Szczególnie w warunkach festiwali, kłóre maja określony czas i reguły organizacyjne. Dlatego częściej w miastach możemy zobaczyć prace o akceptowalnej społecznie tematyce, o historycznej ikonografii, będace eksperymentem w przestrzeni wpisującym się w ideę nowoczesnych przestrzeni miejskich, o kłórych pisze Ewa Rewers ${ }^{25}$. Malarstwo autorstwa duetu Etam Cru26, znanych i tworza-

${ }^{20}$ Jane Jacobs - dziennikarka, kłóra miała wymierny wpływ na amerykańska urbanistykę XX wieku, twierdziła, że miasta potrzebuja różnorodności pod każdym względem - również architektonicznym, ponieważ zbył ekskluzywne dzielnice nie zapewnia przestrzeniom publicznym charakteru publicznych; [W:] J. Jacobs, 2014. Śmierć i życie wielkich miast Ameryki. Wyd. Centrum Architekturys, 157-233.

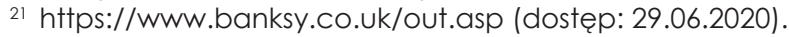

22 Daniela Zedda, mimo bardzo osadzonego w tożsamości projektu, jakim jest „Quanta strada nei miei sandali", prezentuje prace bez otoczenia, tylko w zakresie eksponowanego zdjęcia.

${ }^{23}$ „Paesani”, projekt fotograficzny pokazujacy 41 uczestników Festival letterario L'Isola delle Storie, autorka: Daniela Zedda, 2017, http://www.danielazedda.it (dostęp: 29.06.2020).

${ }^{24}$ Sztuka site-specific zaistniała po raz pierwszy pod koniec lat 60. i na poczattku lat 70. XX wieku, początkowo zwiqzana była z miejscem, potem z krytyka kontekstu, a następnie poddała się procesom estetyzacji i partycypacji; M. Kwon, 2004. One place after another. Site-specific art and locational identity, Londyn, 4.

${ }^{25}$ E. Rewers, 2018. Kulturowe studia miejskie. Wprowadzenie, Narodowe Centrum Kultury.

${ }^{26}$ Duet Ełam Cru tworza artyści Mateusz Gapski (pdeudonim: Bezt) i Przemek Blejzyk (pseudonim: Sainer). 

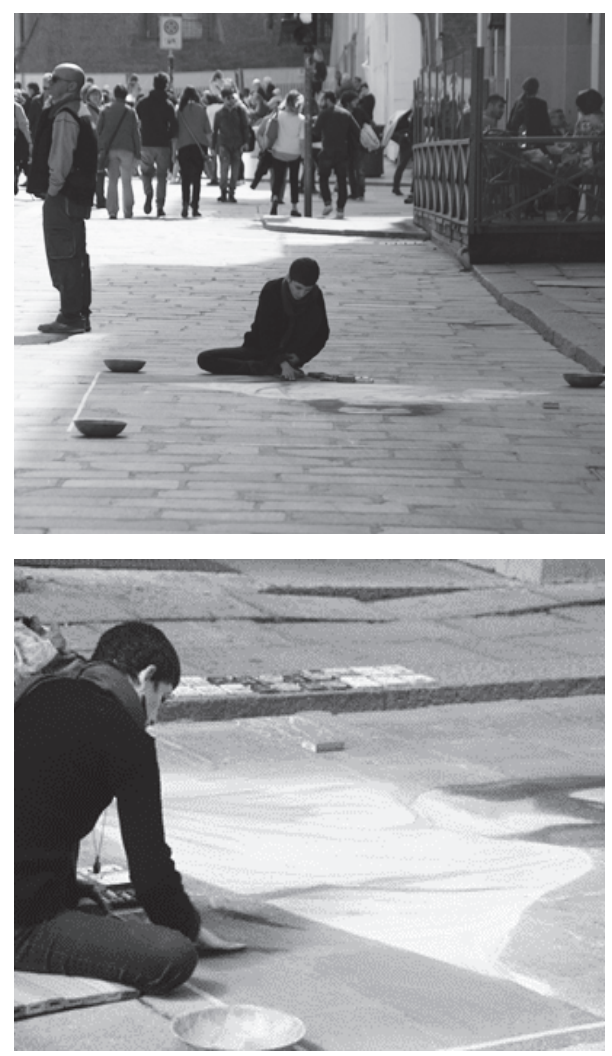

Rys. 6. Portret Jezusa Chrystusa malowany suchymi pastelami na bruku w Bolonii we Włoszech (fot. autor, 2020)

Fig. 6. Ritratto di Gesù Cristo dipinto con pastelli secchi su un marciapiede a Bologna, Italia (photo by author 2020)

cych w świece artystów, to przykład nie tylko wydarzenia w mieście, ale przede wszystkim wysokiego kunsztu artystycznego, kłóry może zdefiniować na nowo estetkę danego miejsca. Zastosowanie techniki 3D w malarstwie może wykreować nowe relacje przestrzenne pomiędzy iluzja a rzeczywistościa. Głębia i perspektywa, często oparte tematycznie na rysunku panoramy lub fragmencie miasta $^{27}$, to wyobrażenie idealnej, ciekawej przestrzeni. Ta wciąż rozwijająca się technika jest inspirująca ${ }^{28}$, ponieważ jej wpływ na percepcję istniejacej przestrzeni jest nadal niezgłębiony. Aktualnie zachwyca wyrazem i iluzją, jednak odpowiednio użyła może poprawiać proporcję wnętrz, tak aby można było zmienić ich odbiór z rozległych czy przyłłaczajacych na proporcjonalne ${ }^{29}$. Jednak zachwianie równowagi pomiędzy eksperymentem w przestrzeni publicznej a zastanym charakterem przestrzeni architektonicznej jest szczególnie trudne w sytuacji multiplikacji dzieł, która jest ściśle zwiq̨zana z festiwalowym procesem powstawania wielkoformatowych prac artystycznych. Murale poprzez intensywność wyrazu i występowania tworza własny charakter miejsca, a nawet drogę poruszania się po mieście, która może stać się turystycznym szlakiem zwiedzania. Dzieła tworza nowe punkty orientacyjne w przestrzeni, po której poruszaja się zarówno mieszańcy, jak i turyści. Z moich własnych obserwacji wynika, że prace moga wpływać na ruch i kierunek obranej przez przechodnia drogi. Artystka rysująca postać Jezusa na brukach Bolonii (rys. 6) gromadziła widzów wokół, powodowała spowolnienie ruchu, zatrzymanie lub obejście pracy w procesie tworzenia i potem w czasie

27 Przykładem wielkoformatowej sztuki 3D w mieście, docenionej przez środowisko architektoniczne, jest praca pt.: „Opowieść śródecka z trębaczem na dachu i kotem w tle". Mural powstał na rogu ulic Śródka i Rynek w Poznaniu i w 2016 roku otrzymał wyróżnienie od Stowarzyszenia Architektów Polskich.

${ }^{28}$ Wyjawiaja się dwa główne tematy malarstwa 3D. Pierwszy to iluzja otwartego wnętrza, drugi typ to obrazy przedstawiajace panoramy zabudowy architektonicznej; [za:] A. Gralińska-Toborek, 2016. Street Art and Spac. [W:] A. Gralińska-Toborek, W. Kazimierska-Jerzyk, Aesthetic Energy of the City. Wyd. Uniwersytetu Łódzkiego, Łódź.

29 Wnętrza rozległe - o kącie środkowym ok. 10 stopni; wnętrza proporcjonalne - o kacie środkowym ok. 25-45 stopni; wnętrza przyłłaczajace - o kqcie środkowym ok. 60 stopni. [W:] P. Lorens, J. Pęczak, 2014. Wprowadzenie do projektowania urbanistycznego. Akapit-DTP, Gdańsk. 
żywotności dzieła. Wydzielenie pola na dzieło z pasa komunikacji jest wyraźnie zaznaczone i wpływa na zachowanie przechodniów.

Wpływ dzieła szłuki na łło architektoniczne może mieć również wymiar finansowy. Znaczace dzieło może podnieść wartość na rynku nieruchomości, a dzieło o wątpliwych walorach estetycznych może obniżyć jego rangę. Zagadnienie dodatkowo komplikuje się w przypadku prac powstałych $w$ nielegalnym procesie tworzenia, ale twórczość Banksy'ego pokazuje, że tego typu prace $^{30}$ również moga wpływać wymiernie na wycenę budynku, na kłórym powstana.

\section{PODSUMOWANIE}

Podsumowujac rozważania na temat sztuki w przestrzeni publicznej, należy przyjać jej istnienie za fakt i odpowiedź na potrzebę zmienności, atrakcyjności i wolności w mieście. Sztuka w formie wolnostojących obiektów, niezwiq̨zanych z budynkiem, wpływa na percepcję architektury w nieznacznym stopniu, ale eksponowana bezpośrednio na jej tle, w powiqzaniu lub nawet bezpośrednio na jej płaszczyznach, może zmieniać jej odbiór w przestrzeni, charakłer estetyczny i jakościowy. Jeżeli podążajac za zasadami Lyncha ${ }^{31}$, postrzegamy architekturę jako element trwały, tworzący relacje przestrzenne, budujący poczucie tożsamości, bezpieczeństwa, powinniśmy zadbać, żeby struktura architekłoniczna nie uległa zniszczeniu. Oczywiście poszczególne elementy moga się zmieniać, jednak najważniejsze budynki pełniace rolę dominant fizycznych i psychologicznych, lokalizowane w węzłach, powinny pozostać trwałymi elementami przestrzeni architektonicznej miast. Christian Norbert-Schulz uważał, że człowiek musi dbać o struktury, w kłórych wzrastał, a jego działania W przestrzeni architektonicznej powinny polegać „....z jednej strony, na próbie zintegrowania jej struktury z osobistymi schematami, a z drugiej - na przełożeniu swoich schematów na konkretne struktury architektoniczne"32. Brak w dialogu sztuka - miasto głosu architekta skutkuje zachwianiem czytelności struktury architektonicznej, chaosem estetycznym, stawianiem architektury w roli nie tyle łła czy kontekstu przestrzennego, co jedynie nośnika, stelaża dzieła sztuki. Być może stworzenie przez grupę uwarunkowań umocowanych w dokumentach formalno-prawnych zmniejszy ryzyko konfliktu na styku sztuki z architektura i określi proporcje pomiędzy nimi. Współpraca pomiędzy artystami i architektami może pozyływnie wpłynać na percepcję zarówno dzieła, jak i powiąanej z nim formy architektonicznej. Edukacja każdej z grup może przynieść nowe możliwości rozwoju obu dziedzin. Ograniczenia nie sa możliwe, a nawet wskazane dla wszystkich form street-artu, jednak stosowane do legalnych przedsięwzięć moga nieść za soba aspekt edukacyjny i wpływać również na nielegalne działania artystyczne w przestrzeni publicznej.

${ }^{30}$ Graffiti Banksy'ego, przedstawiajace całujących się policjantów, wykonane na ścianie pubu Prince Albert w Brighton, zostało sprzedane na za 575 tys. dolarów, zdarzały się również kradzieże, co jest paradoksalne, ponieważ niektóre instyłucje chronia jego nielegalne prace, chociaż wcześniej uznawały je za akł wandalizmu.

${ }^{31}$ K. Lynch, 1990. The image of the city. Wyd. Kevin Lynch, The Image of the City The M.I.T. Press, Londyn, s.109-111.

${ }^{32}$ Ch. Norberg-Schulz, 2000. Bycie, przestrzeń i architektura. Wyd. Murator, 37. 


\section{LITERATURA}

[1] Buczyńska-Garewicz H., 2006. Miejsca, strony, okolice. Przyczynek do fenomenologii przestrzeni. Wyd. Universitas, Kraków.

[2] Duchowski M., Drozda J., Kopczyński B., Litorowicz A., Pietraszko A., Rojek Z, Welter E., Wittels K., 2017. Projekt badawczy „Mury. Diagnoza dynamiki środowiska twórców malarstwa monumentalnego". Instyłut Badań Przestrzeni Publicznej w partnerstwie z Centrum Sztuki Współczesnej „Łaźnia” oraz Muzeum Współczesnym, Wrocław.

[3] Gralińska-Toborek A., Kazimierska-Jerzyk W., 2016. Aesthetic Energy of the City. Wyd. Uniwersytetu Łódzkiego, Łódź.

[4] Heidegger M., 1974. Budować, mieszkać, myśleć. Teksty: teoria literatury, krytyka, interpretacja, $\mathrm{nr}$ 6(18), 137-152.

[5] Jacobs J., 2014. Śmierć i życie wielkich miast Ameryki. Wyd. Centrum Architektury.

[6] Kaznowski M., 2018. Mur(al)owe podwoje do przeszłości - murale jako nośniki kultury historycznej. Zeszyty Naukowe Towarzystwa Doktorantów Uniwersytetu Jagiellońskiego, Nauki Społeczne, Kraków.

[7] Kerr R., 2014. The Belfast Mural Guide. Wyd. MSF Press.

[8] Klimczuk A., 2013. Hipoteza Sapira-Whorfa - przeglad argumentów zwolenników i przeciwników. Kultura - Społeczeństwo - Edukacja, 1 (3), 165181, Adam Mickiewicz University Press, Poznań.

[9] Kwon M., 2004. One place after another. Site-specific art and locational identity. Londyn.

[10] Lynch K.,1990. The image of the city. Wyd. Kevin Lynch, The Image of the City The M.I.T. Press, Londyn.

[11] McLuhan M., Now The Medium Is The Massage. New York Times, pobrano: 04.09.2018.

[12] Moch W., 2016. Street art i graffiti. Litery, słowa i obrazy w przestrzeni miasta. Wyd. Uczelniane Wyższej Szkoły Gospodarki \& Włodzimierz Moch, Bydgoszcz.

[13] Niżyńska A., 2011. Street art jako alternatywna forma debaty publicznej w przestrzeni miejskie. Wyd. Trio, Warszawa.

[14] Norberg-Schulz Ch., 2000. Bycie, przestrzeń i architektura. Wyd. Murator.

[15] Rewers E., 2018. Kulturowe studia miejskie. Wprowadzenie. Narodowe Centrum Kultury.

[16] Żygulski Z., 1981. Przestrzeń muzealna. [W:] Mecenas, kolekcjoner, odbiorca. Materiały Sesji Stowarzyszenia Historyków Sztuki, Katowice, listopad 1981, Warszawa 1984, 243-255.

\section{SZTUKA WIELKOFORMATOWA NA TLE ARCHITEKTURY, ZJAWISKO I JEJ WPŁYW NA PERCEPCJĘ PRZESTRZENI I FORMY ARCHITEKTONICZNEJ}

STRESZCZENIE. Przestrzeń i forma architektoniczna zawsze były miejscem ekspozycji sztuki, również współcześnie sztuka w przestrzeni publicznej jest zjawiskiem popularnym. Przestrzeń publiczna ze względu na swój charakter, kontekst i nieograniczony dostęp do odbiorcy jest szczególnie atrakcyjna dla artystów poszukujacych kontaktu z odbiorca, dlatego w mia- 
stach pojawia się sztuka zaangażowana politycznie, społecznie i oczywiście sztuka komercyjna. Artyści, tworzac swoje dzieła, szukaja inspiracji w kontekście konkretnego miejsca, które staje się niejako częścia dzieła. Jednak dzieło również wpływa na przestrzeń, architekturę i jej odbiór. Zmienia, a nawet zaburza utarty lub zaplanowany ruch w przestrzeni, przejmuje rolę dominanty wizualnej, a nawet odbiór wymiarów przestrzeni i formy.

Słowa kluczowe: sztuka wielkoformatowa, percepcja, zmysły, architektoniczna przestrzeń

\section{LARGE-FORMAT ART AGAINST THE BACKGROUND OF ARCHITECTURE, THE PHENOMENON AND ITS IMPACT ON THE PERCEPTION OF SPACE AND ARCHITECTURAL FORM}

SUMMARY. Space and architectural form have always been a place of art exhibition, also now art in public space is a popular phenomenon. Public space, due to its nature, context and unlimited access to the recipient, is particularly attractive for artists seeking contact with the recipient, which is why art that is politically, socially and, of course, commercial art appears in cities. When artists create their works, they look for inspiration in the context of a specific place, which in a way becomes part of the work. However, the work also influences space, architecture, and its reception. It changes and even disturbs the usual or planned movement in space, it takes on the role of a visual dominant and even the perception of space and form.

Key words: large format art, perception, senses, architectural space 